\title{
Brain-Derived Neurotrophic Factor Promotes the Survival and Sprouting of Serotonergic Axons in Rat Brain
}

\author{
Laura A. Mamounas, ${ }^{1}$ Mary E. Blue, ${ }^{2}$ Judith A. Siuciak, ${ }^{3}$ and C. Anthony Altar ${ }^{3}$ \\ 'Laboratory of Cellular and Molecular Biology, Gerontology Research Center, National Institute on Aging, National \\ Institutes of Health, Baltimore, Maryland 21224, ${ }^{2}$ The Kennedy-Krieger Research Institute and Department of \\ Neurology, The Johns Hopkins University School of Medicine, Baltimore, Maryland 21205, and ${ }^{3}$ Regeneron \\ Pharmaceuticals, Inc., Tarrytown, New York 10591
}

\begin{abstract}
A pathology of brain serotonergic (5-HT) systems has been found in psychiatric disturbances, normal aging and in neurodegenerative disorders including Alzheimer's and Parkinson's disease. Despite the clinical importance of 5-HT, little is known about the endogenous factors that have neurotrophic influences upon 5-HT neurons. The present study examined whether chronic brain parenchymal administration of the neurotrophins brain-derived neurotrophic factor (BDNF), neurotrophin-3 (NT-3) or NGF could prevent the severe degenerative loss of serotonergic axons normally caused by the selective $5-\mathrm{HT}$ neurotoxin $p$ chloroamphetamine (PCA). The neurotrophins (5-12 $\mu \mathrm{g} / \mathrm{d}$ ) or the control substances (cytochrome $c$ or PBS vehicle) were continuously infused into the rat frontoparietal cortex using an osmotic minipump. One week later, rats were subcutaneously administered PCA $(10 \mathrm{mg} / \mathrm{kg})$ or vehicle, and the 5-HT innervation was evaluated after two more weeks of neurotrophin infusion. As revealed with 5-HT immunocytochemistry, BDNF infusions into the neocortex of intact (non-PCA-lesioned) rats caused a substantial increase in 5-HT axon density in a $3 \mathrm{~mm}$ diameter region surrounding the cannula tip. In PCA-lesioned rats, intracortical infusions of BDNF completely prevented the severe neurotoxin-induced loss of 5-HT axons near the infusion cannula. In contrast, cortical infusions of vehicle or the control protein cytochrome $c$ did not alter the density of serotonergic axons in intact animals, nor did control infusions prevent the loss of 5-HT axons in PCA-treated rats. NT-3 caused only a modest sparing of the 5- $\mathrm{HT}$ innervation in PCA-treated rats, and NGF failed to prevent the loss of 5-HT axon density. The immunocytochemical data were supported by neurochemical evaluations which showed that BDNF attenuated the PCA-induced loss of 5-HT and 5-HIAA contents
\end{abstract}

\footnotetext{
Received Jan. 24, 1995; Ievised July 25, 1995; accepted Aug. 4, 1995.

We thank Dr. Efrain Azmitia and Dr. W. Ernest Lyons for critical review of the manuscript. We greatly appreciate the assistance of Ms. Carolyn Boylan and Ms. Michelle Fritsche in conducting the surgical procedures and 5-HT uptake assays and Ms. Mary S. Lange in conducting the immunocytochemistry. We also thank Dr. Randy Hecht from AMGEN, Inc., for the generous supply of recombinant human NGF, the AMGEN-Regeneron Partnership for the supply of BDNF and NT-3, and AMGEN Pharmaceuticals for providing the turkey anti-BDNF antibody. This work was supported in part by NIH Grant NS29167 to M.E.B.

Correspondence should be addressed to Dr. Laura A. Mamounas, Laboratory of Cellular and Molecular Biology, Gerontology Research Center, National Institute on Aging, National Institutes of Health, 4940 Fastern Avenue, Baltimore, MD 21224.

Copyright $\odot 1995$ Society for Neuroscience $0270-6474 / 95 / 157929-11 \$ 05.00 / 0$
}

and ${ }^{3} \mathrm{H}-5-\mathrm{HT}$ uptake near the infusion cannula. Thus, BDNF can promote the sprouting of mature, uninjured serotonergic axons and dramatically enhance the survival or sprouting of 5-HT axons normally damaged by the serotonergic neurotoxin PCA.

[Key words: brain-derived neurotrophic factor, neurotrophin-3, NGF, neurotrophic, 5-HT, p-chloroamphetamine, neurodegeneration, regeneration]

Extensive research in recent years has shown that small proteins called neurotrophins have profound influences upon the development, survival, regulation of function, and plasticity of diverse neuronal populations in both the CNS and PNS (reviewed by Levi-Montalcini, 1987; Lindsay et al., 1994). The neurotrophins comprise a family of homologous proteins which includes nerve growth factor (NGF), brain-derived neurotrophic factor (BDNF), neurotrophin-3 (NT-3), and neurotrophin-4/5 (NT-4/5). Despite the $50-55 \%$ similarity in the amino acid composition of these molecules (Hohn et al., 1990; Maisonpierre et al., 1990), the different neurotrophins promote the survival of distinct, yet overlapping, sets of central and peripheral neurons. For example, sympathetic neurons respond to NGF and NT-3 but not to BDNF (Maisonpierre et al., 1990; Rosenthal et al., 1990), while cultured mesencephalic dopamine neurons respond to BDNF and NT-3 but not to NGF (Hyman et al., 1994). On the other hand, both NGF and BDNF support the survival and differentiation of cholinergic neurons in the basal forebrain (Alderson et al., 1990; Knüsel et al., 1991). Because the neurotrophins can prevent the degeneration or facilitate recovery of injured neurons in the adult nervous system, these factors have been proposed as potential therapeutic agents for treating the structural deterioration of neurons that occurs during aging or in neurodegenerative diseases (reviewed by Hefti et al., 1989; Gage et al., 1990; Lindsay et al., 1994).

An impaired function of brain serotonergic (5-HT) systems has been implicated in a number of neurologic disturbances including the major depressive disorders, anxiety, obsessive-compulsive behavior, migraine, and obesity (Whitaker-Azmitia and Peroutka, 1990). Furthermore, the recreationally abused drugs methamphetamine, 3,4-methylenedioxyamphetamine (MDA) and 3,4-methylenedioxymethamphetamine (MDMA) and the clinically prescribed anorectic agent fenfluramine cause an extensive degeneration of serotonergic axons in laboratory animals, including nonhuman primates (reviewed by McCann and Ricaurte, 1994). A recent study by McCann et al. (1994) indicates that MDMA (or "Ecstasy") use in humans may lead to 5-HT neurotoxicity in the brain. Serotonergic pathology has also been 


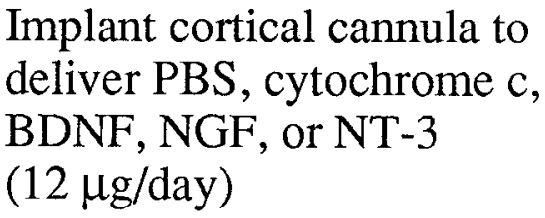

Implant cortical cannula to deliver PBS, cytochrome c, $(12 \mu \mathrm{g} /$ day $)$

\author{
Subcutancous \\ injection of \\ PCA $(10 \mathrm{mg} / \mathrm{kg})$ \\ or saline vehicle
}

\author{
Sacrifice for 5-HT \\ immunocytochemistry \\ or neurochemical \\ measures
}

\section{Day $0 \longrightarrow 6 \longrightarrow 21$}

Figure 1. Time-line of the experimental paradigm. BDNF $(12 \mu \mathrm{g} / \mathrm{d}), \mathrm{NT}-3(12 \mu \mathrm{g} / \mathrm{d})$, or NGF $(5.4 \mu \mathrm{g} / \mathrm{d})$, or the control substances insect cytochrome c $(12 \mu \mathrm{g} / \mathrm{d})$ or vehicle (sterile PBS) were continously infused into the right frontoparietal cortex over a 3 week period via a cannula connected to an osmotic minipump. One week after the start of the intracortical infusion, rats were administered one subcutaneous injection of either PCA $(10 \mathrm{mg} / \mathrm{kg})$ or saline vehicle. Two weeks after PCA (or vehicle) administration, rats were sacrificed and the brains prepared for immunocytochemical staining of 5-HT neurons or neurochemical measurements of 5-HT and 5-HIAA levels and high-affinity ${ }^{3} \mathrm{H}-5-\mathrm{HT}$ uptake.

found in aged rats (van Luijtelaar et al., 1992) and in human age-related neurodegenerative disorders. On a par with cholinergic neuron loss, there is a profound loss of 5-HT neurons and their processes in Alzheimer's disease (Cross, 1990), and 5-HT neurons are extensively depleted in Parkinson's disease (Agid et al., 1992). Despite the clinical importance of serotonin, very little is known about the endogenous factors that have neurotrophic influences upon serotonergic neurons. In vitro experiments have shown that the astrocyte-derived protein S-100ß enhances the neurite outgrowth, but not survival, of serotonergic neurons in embryonic raphe cultures (Azmitia et al., 1990; Liu and Lauder, 1992). A soluble, but unidentified, factor extracted from the 5-HT denervated hippocampus can markedly cnhance the survival and sprouting of grafted serotonergic neurons in the cerebellum (Zou and Azmitia, 1990). These findings suggest the existence in brain of an endogenous survival factor for serotonergic neurons.

Several recent in vivo studies suggest that some members of the neurotrophin family have functional influences upon serotonergic neurons in the brain. High-affinity binding sites for ${ }^{125} \mathbf{I}-$ NT-3 (Altar et al., 1993) and mRNA transcripts for trkB and trkC, the signal-transducing receptors for BDNF and NT-3, respectively (Merlio et al., 1992), are found in the dorsal raphe nucleus. Moreover, BDNF is retrogradely transported from 5-HT terminal fields in the striatum and hippocampus to cell bodies in the raphe nuclei (Anderson et al., 1995). Finally, BDNF, and to a lesser extent NT-3, greatly augment 5-HT metabolism and potentiate 5-HT-related behaviors when chronically infused into the substantia nigra (Altar et al., 1994; Martin-Iverson et al., 1994) or in the midbrain region near the dorsal raphe and periaqueductal gray (Siuciak et al., 1994). Presently, it is not known whether the neurotrophins can protect serotonergic neurons from injury or induce the sprouting of 5-HT axons in the brain.

The present study examined whether BDNF, NT-3, or NGF could protect serotonergic neurons in the adult rat brain from chemical axotomy. Normally, serotonergic axons densely innervate most areas of the brain and spinal cord, and arise almost exclusively from cell bodies located in the raphe nuclei of the brainstem (reviewed by Molliver, 1987). Systemic administration of the selective 5-HT neurotoxin $p$-chloroamphetamine (PCA), or other neurotoxic amphetamine derivatives such as MDA, MDMA, or fenfluramine, cause a rapid degeneration of most serotonergic axon terminals in the forebrain, while sparing 5-HT cell bodies in the raphe nuclei and preterminal fibers (Ma- mounas and Molliver, 1988; O'Hearn et al., 1988; Appel et al., 1989; Mamounas et al., 1991; Axt et al., 1992). This pruning of 5-HT axon terminals while sparing their cell bodies leads to a slow, progressive sprouting response from the damaged 5-HT axons in cortex that begins about 1-2 months after PCA treatment (Mamounas et al., 1992; Axt et al., 1994). In the present study, we assessed whether continuous infusion of BDNF, NT3 , or NGF into rat frontoparietal cortex could prevent the severe loss of serotonergic axons that is normally observed 2 weeks after systemic administration of PCA.

\section{Materials and Methods}

Experimental paradigm. Adult male, Sprague Dawley rats (200 220 $\mathrm{gm}$ at the start of the experiment; $n=4-14$ /group) were housed and treated in compliance with AALAC guidelines. Recombinant human BDNF $(2 \mu \mathrm{g} / \mu \mathrm{l} ; 12 \mu \mathrm{g} / \mathrm{d})$, NT-3 $(2 \mu \mathrm{g} / \mu \mathrm{l} ; 12 \mu \mathrm{g} / \mathrm{d})$ or NGF $(0.9 \mu \mathrm{g} /$ $\mu \mathrm{l} ; 5.4 \mu \mathrm{g} / \mathrm{d})$, or the control substances insect cytochrome $\mathrm{c}(2 \mu \mathrm{g} / \mu \mathrm{l}$; $12 \mu \mathrm{g} / \mathrm{d}$ ) or vehicle (sterile PBS) were continously infused into the right neocortex over a 3 week period via a cannula connected to an osmotic minipump (Fig. 1). One week after the start of the intracortical infusion, rats were administered one subcutaneous injection of either d-l, PCA $(10 \mathrm{mg} / \mathrm{kg}$, expressed as the free base; Sigma Chemical Corp., St. Louis, MO) or vehicle (isotonic saline), as described (Mamounas et al., 1991). Two weeks after PCA (or vehicle) administration, rats were sacrificed and the brains prepared for immunocytochemical staining of 5-HT neurons or neurochemical measurements of 5-HT and 5-hydroxyindole acetic acid (5-HIAA) levels and high-affinity ${ }^{3} \mathrm{H}-5-\mathrm{HT}$ uptake. For each animal, the contralateral, noninfused (left) cortex served as an internal control for the extent of 5-HT denervation caused by systemically administered PCA, whereas the ipsilateral (right) cortex infused with vehicle or cytochrome $\mathrm{c}$ served as a between group control for infusion.

Abbreviations used for the treatment groups. The chronic intracortical infusion of the control substances cytochrome $\mathrm{c}$ or PBS produced similar results regarding 5-HT immunocytochemical staining and neurochemical measurements in both intact and PCA-lesioned rats. Therefore, we have assigned the following abbreviations to the different treatment groups employed in this study: veh/veh animals received a unilateral, intracortical infusion of PBS or cytochrome c for 3 weeks followed, 1 week after the start of the infusion, by a subcutaneous injection of saline; veh/PCA animals were infused intracortically with PBS or cytochrome $c$ followed by subcutaneous administration of PCA; $B D N F /$ veh animals were infused intracortically with BDNF followed by a subcutaneous injection of saline; $B D N F / P C A$ animals were infused intracortically with BDNF followed by a subcutaneous injection of PCA; $N G F / P C A$ animals received a unilateral, intracortical infusion of NGF followed by subcutaneous administration of PCA; NT-3/PCA animals received a unilateral intracortical infusion of NT-3 followed by a subcutaneous injection of PCA.

Animal surgery. Alzet 2002 osmotic minipumps (Alza Corp., Palo Alto, CA) were coated $50 \%$ with dental wax to lower the nominal flow rate of $0.5 \mu \mathrm{l} / \mathrm{hr}$ to approximately $0.25 \mu \mathrm{l} / \mathrm{hr}$. The pump was attached 
to a $2 \mathrm{~cm}$ piece of silated PE50 tubing (Micro-Renathane; Braintree Scientific, Braintree, MA) and connected to a $1.6 \mathrm{~mm}$ long, $28 \mathrm{G}$ stainless steel cannula (Plastics One, Roanoke, VA). The pumps and flow moderators were filled with $\mathrm{PBS}$ or with cytochrome $\mathrm{c}$, recombinant human BDNF, NGF, or NT-3 at concentrations of $0.90 \mathrm{mg} / \mathrm{ml}$ (NGF) or $2.0 \mathrm{mg} / \mathrm{ml}$ (all others substances). The lower concentration of NGF was used because of its superior delivery properties and higher affinily for binding to brain compared with BDNF or NT-3. Each rat was anesthetized with an intraperitoneal injection of $149 \mathrm{mg} / \mathrm{kg}$ chlorohydrate and $30.8 \mathrm{mg} / \mathrm{kg}$ sodium pentobarbital and mounted in a small animal stereotaxic apparatus (David Kopf Instruments, Tijunga, CA), A $2 \mathrm{~cm}$ midline incision was made on the scalp, through which the osmotic pump was inserted and implanted in a subcutaneous pocket between the shoulder blades. The cannula was positioned in the right frontoparietal cortex using the following stereotaxic coordinates: $1.8 \mathrm{~mm}$ anterior and $2.0 \mathrm{~mm}$ lateral to bregma, and $1.6 \mathrm{~mm}$ below the skull surface. The cannula was inserted through a $0.5 \mathrm{~mm}$ hole drilled at this location and was glued flush to the skull with cyanoacrylate adhesive. The scalp incision was closed with wound clips.

5-HT and BDNF immunocytochemistry. Animals were deeply anesthetized with chloral hydrate $(400 \mathrm{mg} / \mathrm{kg}$, i.p.) and perfused through the aorta with cold PBS ( $\mathrm{pH} \mathrm{7.4)} \mathrm{followed} \mathrm{by} 4 \%$ paraformaldehyde in 0.15 M phosphate buffer ( $\mathrm{pH} 7.4$ ). Brains were postfixed for $4-6 \mathrm{hr}$ at $4^{\circ} \mathrm{C}$, and then cyroprotected in $20-30 \%$ sucrose $\left(4^{\circ} \mathrm{C}\right)$ for $3 \mathrm{~d}$. Coronal sections through the cannula site were cut frozen at $30 \mu \mathrm{m}$ on a sliding microtome. Free-floating sections were incubated in antiserum directed against 5-HT (Incstar Corp., Stillwater, MN), diluted 1:15,000 (Mamounas et al., 1991). To assess the intracerebral distribution of the infused BDNF, adjacent sections were incubated with a turkey anti-BDNF antibody (Amgen, Inc.) at a dilution of 1:7,500 (Morse et al., 1993). Bound immunoglobulin was visualized with the avidin-biotin-peroxidase method (Vector Laboratories, Burlingame, CA), using diaminobenzidine tetrachloride as the substrate. Staining of 5-HT axons in cortex was not observed when the primary or secondary antibodies were omitted from the respective incubation mixtures.

Indoleamine concentrations and high affinity 5-HT uptake. Each brain was rapidly excised and placed on an ice-chilled metal block. A $3.0 \mathrm{~mm}$ OD diameter stainless steel tube (approx. $2.5 \mathrm{~mm}$ ID) was centered over the cortical region of cannula penetration and lowered through the cortex. The tube was removed and the cylinder of cortical tissue was excised by separating it from the dorsal surface of the corpus callosum. Other cortical cylinders were similarly prepared in the contralateral frontoparietal cortex and bilaterally in the occipital cortex. The cortical cylinders were weighed and homogenized in $200 \mu \mathrm{l}$ of $0.32 \mathrm{M}$ sucrose. One $45 \mu \mathrm{l}$ aliquot of this homogenate was immediately acidified and assayed for 5-HT and 5-HIAA contents by HPLC with electrochemical detection, using the ESA 16 channel coulometric array detector system (CEAS 5300; ESA, Inc, Bedford, MA; Gamache et al., 1993). Other $10 \mu \mathrm{l}$ aliquots of the tissue homogenate were immediately assayed for ${ }^{3} \mathrm{H}-5-\mathrm{HT}$ uptake in Krebs-Ringer solution containing $10 \mu \mathrm{M}$ pargyline and $20 \mathrm{~nm}{ }^{3} \mathrm{H}-5-\mathrm{HT}$ (total volume $200 \mu \mathrm{l}$ ). Samples were vortexed, incubated for $10 \mathrm{~min}$ at $37^{\circ} \mathrm{C}$, and rapidly filtered three times with cold buffer. Nonspecific uptake was defined by the addition of 10 $\mu \mathrm{M}$ clomipramine to the buffer while incubating at $0^{\circ} \mathrm{C}$. For studies examining the in vitro effects of BDNF (or NT-3) on ${ }^{3} \mathrm{H}-5-\mathrm{HT}$ uptake into the neocortex of untreated animals, $10 \mu \mathrm{l}$ of BDNF was added to both total and nonspecific samples for a final concentration of BDNF ranging from $20 \mathrm{pM}$ to $2 \mu \mathrm{M}$. Protein determinations were carried out using the BCA protein kit (Pierce, Rockford, IL).

Statistical analysis. The statistical significance of changes in neurochemical measurements was assessed with a $2 \times 2 \times 2$ (PCA treatment $x$ BDNF infusion $x$ side of cortex) analysis of variance (ANOVA) with repeated measures on side of cortex. In the case of significant main effects or interactions, post hoc comparisons were performed using the Newman-Keuls multiple range test. To minimize the between-animal variability in the magnitude of the PCA lesion, the data were also analyzed by calculating the ratio of the neurochemical measure (5-HT or 5-HIAA concentration or ${ }^{3} \mathrm{H}-5-\mathrm{HT}$ uptake) in the infused (right) cortex relative to the contralateral (noninfused) cortex for each animal. The ratio data were analyzed with a $2 \times 2$ (PCA treatment $\times$ BDNF infusion) ANOVA, followed by the Newman-Keuls multiple range test.

\section{Results}

\section{5-HT immunocytochemistry}

Intracortical infusions of vehicle in intact and PCA-treated animals. In control rats (veh/veh; see Materials and Methods sec- tion for abbreviations and Fig. 1, for expcrimental design), there was a high density of 5-HT-immunoreactive axons throughout cortex (Figs. 2, 3: veh/veh), as previously observed in intact, non PCA-lesioned rats (Blue et al., 1988; Mamounas et al., 1991). Three week infusions of cytochrome $\mathrm{c}(n=4)$ or PBS $(n=5)$ into frontoparietal cortex of intact rats (veh/veh) produced a small zone $(0.1-0.2 \mathrm{~mm})$ of nonspecific tissue necrosis immediately adjacent to the cannula site, but there was no change in the density or morphology of 5-HT-immunoreactive fibers in the region surrounding the cannula or elsewhere in cortex (Fig. 2). Subcutaneous administration of PCA to rats with intracortical infusions of cytochrome c or PBS (veh/PCA) caused a dramatic loss of 5-HT axon density throughout cortex, similar to that obtained with PCA treatment alone (Mamounas and Molliver, 1988; Mamounas et al., 1991). Infusions of cytochrome $c$ $(n=7)$ or PBS $(n=7)$ into neocortex had minimal effects upon the severe PC $\Lambda$ induced denervation (Fig. 2). Nlthough a few 5-HT fibers were sometimes found immediately adjacent to the cannula tract, there was still a dramatic loss of 5-HT axon density in the cortical area near the infusion cannula and elsewhere in cortex of veh/PCA animals.

The neurotrophic effects of BDNF upon 5-HT axons in intact and PCA-treated animals. Despite the normally high serotonergic innervation density in the intact cortex, a 3 week intracortical infusion of BDNF in the $B D N F / v e h$ animals caused a substantial increase in 5-HT axon density in an approximately $3 \mathrm{~mm}$ diameter region surrounding the tip of the infusion cannula (Figs. 2, 3). A marked increase in 5-HT axon density was seen in each of the six BDNF/veh animals when compared to control (veh/ veh) animals. Interestingly, the higher axon density was often localized within an approximately $0.5-1 \mathrm{~mm}$ wide annular rim, beginning $0.5-1 \mathrm{~mm}$ from the tip of the BDNF infusion cannula (Fig. 2). Infusion of BDNF into the neocortex of PCA-lesioned rats $(B D N F / P C A)$ prevented the severe neurotoxin-induced loss of serotonergic axons in an approximately $3 \mathrm{~mm}$ diameter region surrounding the tip of the BDNF infusion cannula (Fig. 2). Cortical areas more distant than about $2 \mathrm{~mm}$ from the BDNF infusion site, and the contralateral cortex, were nearly devoid of 5-HT axons in the $B D N F / P C A$ rats. In each of the fourteen $B D N F / P C A$ animals, the 5-HT axon density near the BDNF infusion cannula appeared to be markedly higher than what was found in the veh/PCA control animals. As in the BDNF/veh animals, there was often an annulus of extremely high 5-HT axon density in the $B D N F / P C A$ animals, beginning about $0.5-1 \mathrm{~mm}$ from the BDNF infusion site (Fig. 2). In many cases, the density of 5-HT axons within this annulus appeared to be even higher than the serotonergic innervation density found in the vehicle infused cortex of intact (veh/veh) animals (Figs. 3, 4). The spatial distribution of the spared serotonergic axons surrounding the BDNF infusion cannula corresponded closely with the area of diffusion of the infused BDNF, as revealed in an adjacent section immunostained with an antibody against recombinant human BDNF (Fig. 5). In both $B D N F /$ veh and $B D N F / P C A$ rats, the morphology of the serotonergic axons near the BDNFinfusion cannula resembled 5-HT axon terminals in that most of these fibers were fine with numerous closely spaced, small varicosities (cf., Mamounas et al., 1991). However, the BDNF-exposed 5-HT axons appeared to be slightly thicker, more intensely immunoreactive and more convoluted than those in the homologous cortex of veh/veh animals (Fig. 4).

The effects of NGF and NT-3 on 5-HT axons in PCA-treated rats. Unlike $\mathrm{BDNF}$, infusions of $\mathrm{NGF}$ into the neocortex of 

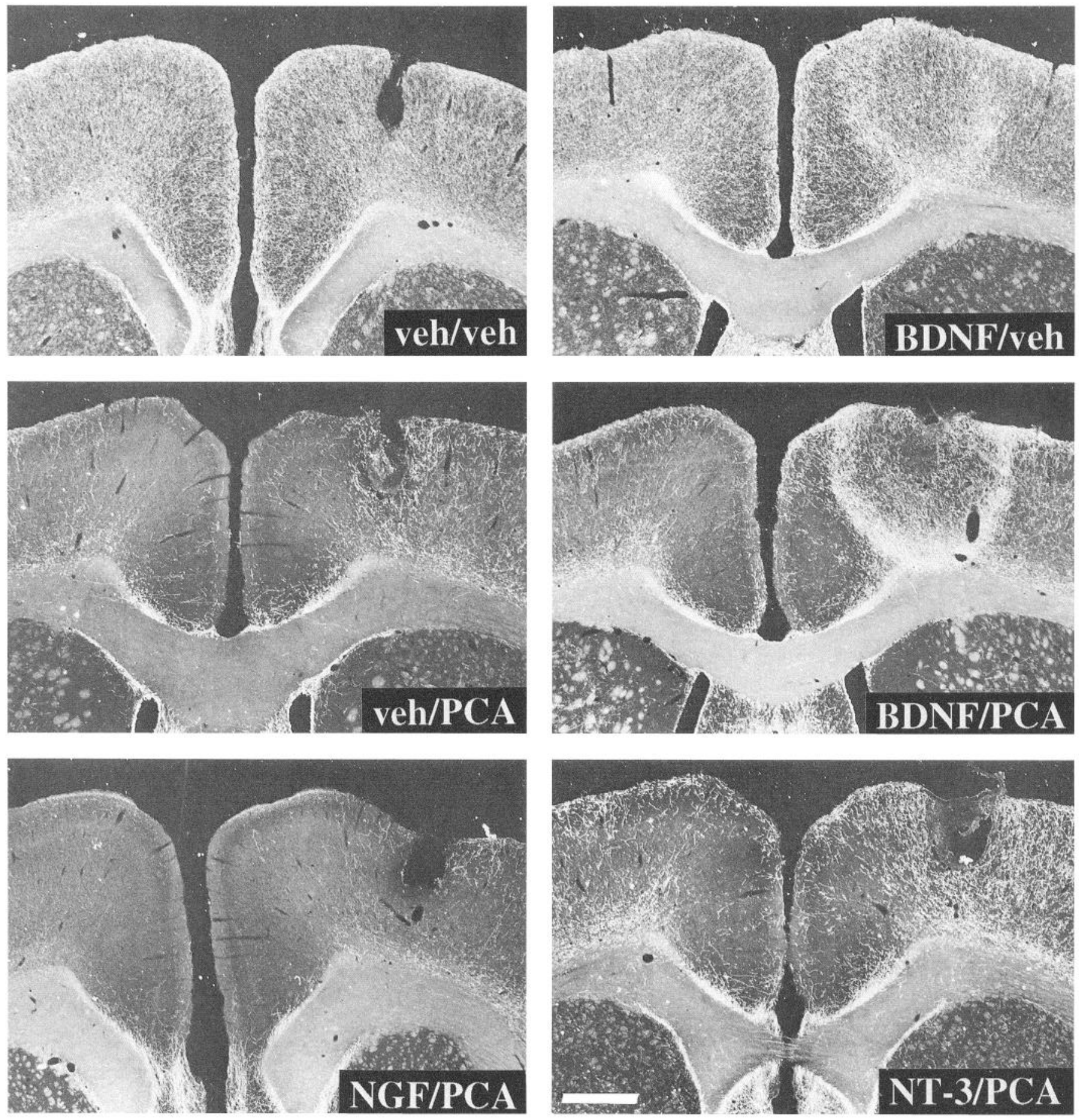

Figure 2. Serotonergic innervation in the rat frontoparietal cortex (coronal sections). Animals were infused with vehicle (veh/), BDNF (BDNF/), NGF (NGF/), or NT-3 (NT-3/) for 3 weeks into the right side of cortex (note cannula tract) followed, 1 week after the start of the infusion, by a subcutaneous injection of vehicle (/veh) or PCA (/PCA). Dark-field photomicrographs depict bright 5-HT-immunoreactive axons on a dark background. Subcutaneous administration of PCA caused a severe loss of 5-HT-immunoreactive axons throughout cortex, except for the dramatic sparing of fibers near the BDNF infusion cannula in the BDNF/PCA animals. Also note the higher 5-HT axon density near the BDNF infusion cannula in the non PCA-lesioned rats $(B D N F / v e h)$. Higher magnification photographs are shown in Figures 3 and 4 . Scale bar, $1 \mathrm{~mm}$.

PCA-lesioned rats $(N G F / P C A ; n=5)$ failed to prevent the loss of 5-HT axon density (Fig. 2). The cortical area near the NGF infusion site was nearly devoid of serotonergic axons, similar to what was seen with vehicle infusions in PCA-treated rats (veh/ $P C A)$. Intracortical infusions of NT-3 in PCA-lesioned rats (NT$3 / P C A ; n=4$ ) produced a modest sparing of the 5-HT inner- vation density in an approximately $3 \mathrm{~mm}$ diameter region surrounding the infusion cannula (Fig. 2). However, NT-3 was much less effective than BDNF in preventing the PCA-induced loss of serotonergic axons. Moreover, the dense annulus of 5-HT axon sparing found in the $B D N F / P C A$ animals was not found in the $N T-3 / P C A$ animals. 

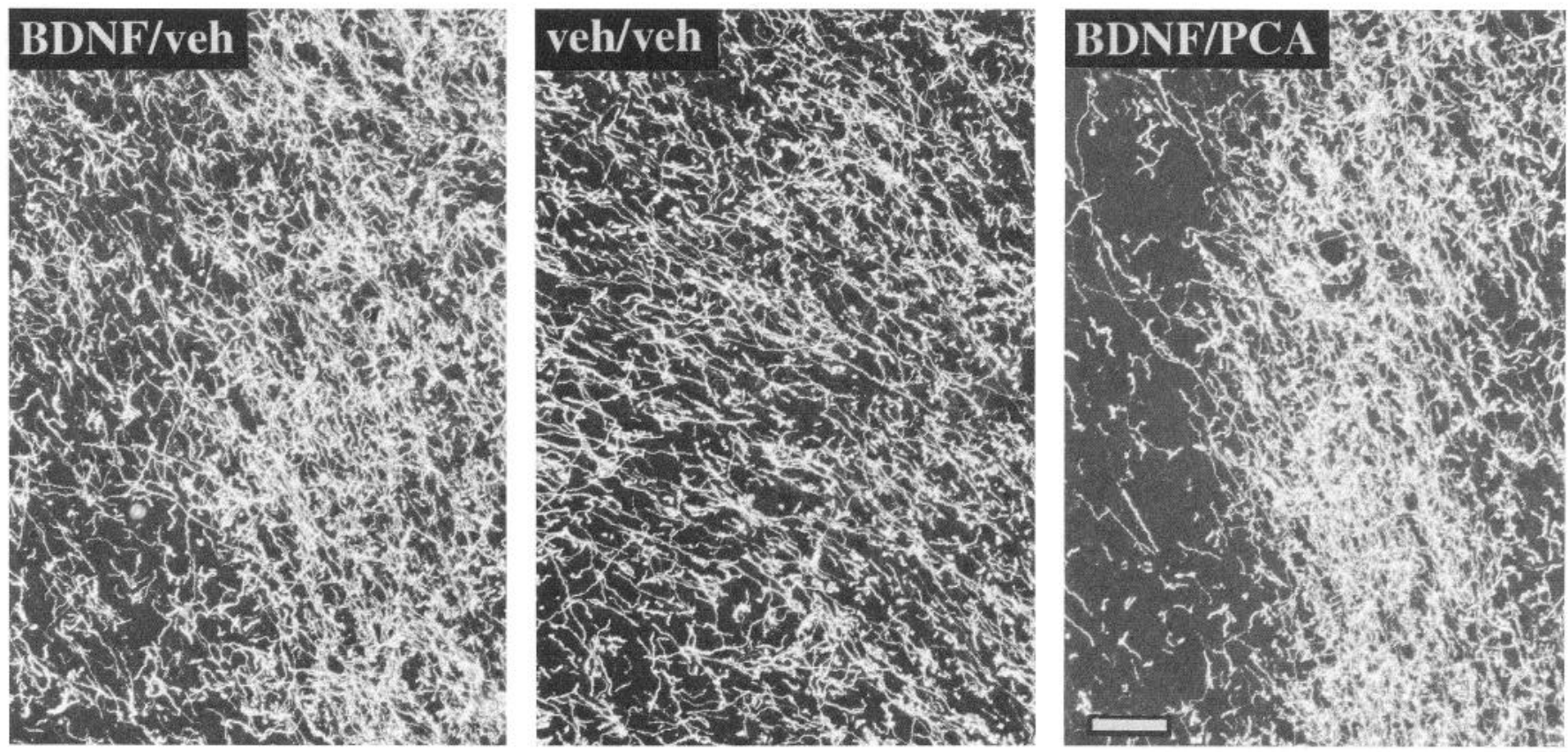

Figure 3. Serotonergic axons near the infusion cannula in rat frontoparietal cortex. Higher magnification dark-field photomicrographs of the "annulus" of higher 5-HT axon density (see Fig. 2; cannula tract is to the right and out of the field of view of each photograph). There is a high density of 5-HT-immunoreactive axons in the vehicle infused cortex of intact rats (veh/veh), but note the supranormal densities of 5-HT axons in the BDNF infused cortex of both PCA-lesioned (BDNF/PCA) and intact (BDNF/veh) animals. Scale bar, $100 \mu \mathrm{m}$.

\section{In vivo neurochemical evaluations}

5-HT and 5-HIAA measurements. Three week intracortical infusions of vehicle did not alter indoleamine concentrations in intact animals: veh/veh animals had similar levels of 5-HT and its metabolite 5-hydroxyindole acetic acid (5-HIAA) in the vehicle infused (right) and contralateral, noninfused (left) frontoparietal cortices (Table 1; three-factor repeated measures ANOVA, followed by the Newman-Keuls multiple range test, $p \geq$ $0.05)$. Subcutaneous administration of PCA caused a significant reduction in cortical levels of 5-HT (Table 1; main effect of PCA treatment: $\left.F_{1,28}=128, p<0.0001\right)$ and 5-HIAA $\left(F_{1,32}=106\right.$, $p<0.0001$ ), as reported previously (Sanders-Bush et al., 1972; Fuller and Snoddy, 1974). Vehicle infusions into the cortex of PCA-lesioned rats (veh/PCA) did not alter indoleamine levels when compared to the contralateral, noninfused cortex (Table 1; $p \geq 0.05)$. In contrast, intracortical infusions of BDNF in PCAlesioned animals $(B D N F / P C A)$ attenuated the decline in 5-HT and 5-HIAA levels in the cortical area surrounding the infusion cannula [Table 1; significant interaction between BDNF infusion and side of cortex for 5-HT $\left(F_{128}=14.2, p<0.001\right)$ and 5-HIAA $\left.\left(F_{1,32}=7.0, p<0.05\right)\right]$. The $B D N F / P C A$ animals showed eightfold and threefold increases in 5-HT and 5-HIAA levels, respectively, in the BDNF infused cortex relative to the contralateral cortex [Fig. 6; two-factor ANOVA on indolamine levels in the infused/contralateral cortex for each animal; for 5-HT: PCA treatment $\left(F_{1,28}=11.6, p<0.005\right)$, BDNF infusion $\left(F_{1,28}=10.6, p<0.005\right)$, interaction between PCA treatment and BDNF infusion $\left(F_{1,28}=8.2, p<0.01\right)$; for 5-HIAA: PCA treatment $\left(F_{1,32}=6.8, p<0.05\right)$, BDNF infusion $\left(F_{1,32}=7.9\right.$, $p<0.01)$ ]. Post hoc Newman-Keuls comparisons showed that, for both 5-HT and 5-HIAA measures, the BDNF/PCA group differed significantly from the three other groups $(p<0.05)$, while none of the other group differences reached statistical sig- nificance (Fig. 6). No significant changes were found in the 5-HT/5-HIAA ratio for any of the groups.

High affinity ${ }^{3} \mathrm{H}-5-\mathrm{HT}$ uptake. Three-week intracortical infusions of vehicle did not alter high affinity ${ }^{3} \mathrm{H}-5-\mathrm{HT}$ uptake in the intact cortex: veh/veh animals showed similar accumulations of ${ }^{3} \mathrm{H}-5-\mathrm{HT}$ in the infused (right) and contralateral (left) frontoparietal cortices (Table 1; three-factor repeated measures ANOVA, followed by the Newman-Keuls multiple range test, $p$ $\geq 0.05$ ). Systemic administration of PCA caused a significant reduction in cortical ${ }^{3} \mathrm{H}-5-\mathrm{HT}$ uptake (Table 1 ; main effect of PCA treatment: $\left.F_{1,32}=122, p<0.0001\right) .{ }^{3} \mathrm{H}-5$-HT uptake in the infused and contralateral cortices of veh/PCA animals was decreased by $63 \%$ and $66 \%$, respectively, from the values found in control (veh/veh) animals. Vehicle infusions into the cortex of PCA-lesioned rats (veh/PCA) did not alter ${ }^{3} \mathrm{H}-5-\mathrm{HT}$ uptake when compared to the contralateral cortex (Table $1 ; p \geq 0.05$ ). However, intracortical infusions of BDNF in PCA-treated animals $(B D N F / P C A)$ increased ${ }^{3} \mathrm{H}-5-\mathrm{HT}$ uptake by twofold relative to the contralateral cortex, thus attenuating the loss of 5-HT uptake normally caused by PCA [Table 1, Fig. 6; two-factor ANOVA on ${ }^{3} \mathrm{H}-5-\mathrm{HT}$ uptake in the infused/contralateral cortex for each animal: PCA treatment $\left(F_{1,32}=8.0, p<0.01\right)$, interaction between PCA treatment and BDNF infusion $\left(F_{1,32}=5.1\right.$, $p<0.05)$ ]. Post hoc Newman-Keuls comparisons showed that the $B D N F / P C A$ group differed significantly from the three other groups $(p<0.05)$, while none of the other group differences reached statistical significance (Fig. 6).

\section{The effects of BDNF on 5-HT uptake in vitro}

Since 5-HT uptake inhibitors such as fluoxetine or citalopram can prevent the PCA-induced degeneration of serotonergic axons in vivo (reviewed by Fuller and Henderson, 1994), we evaluated the in vitro effects of BDNF on ${ }^{3} \mathrm{H}-5-\mathrm{HT}$ uptake in rat 

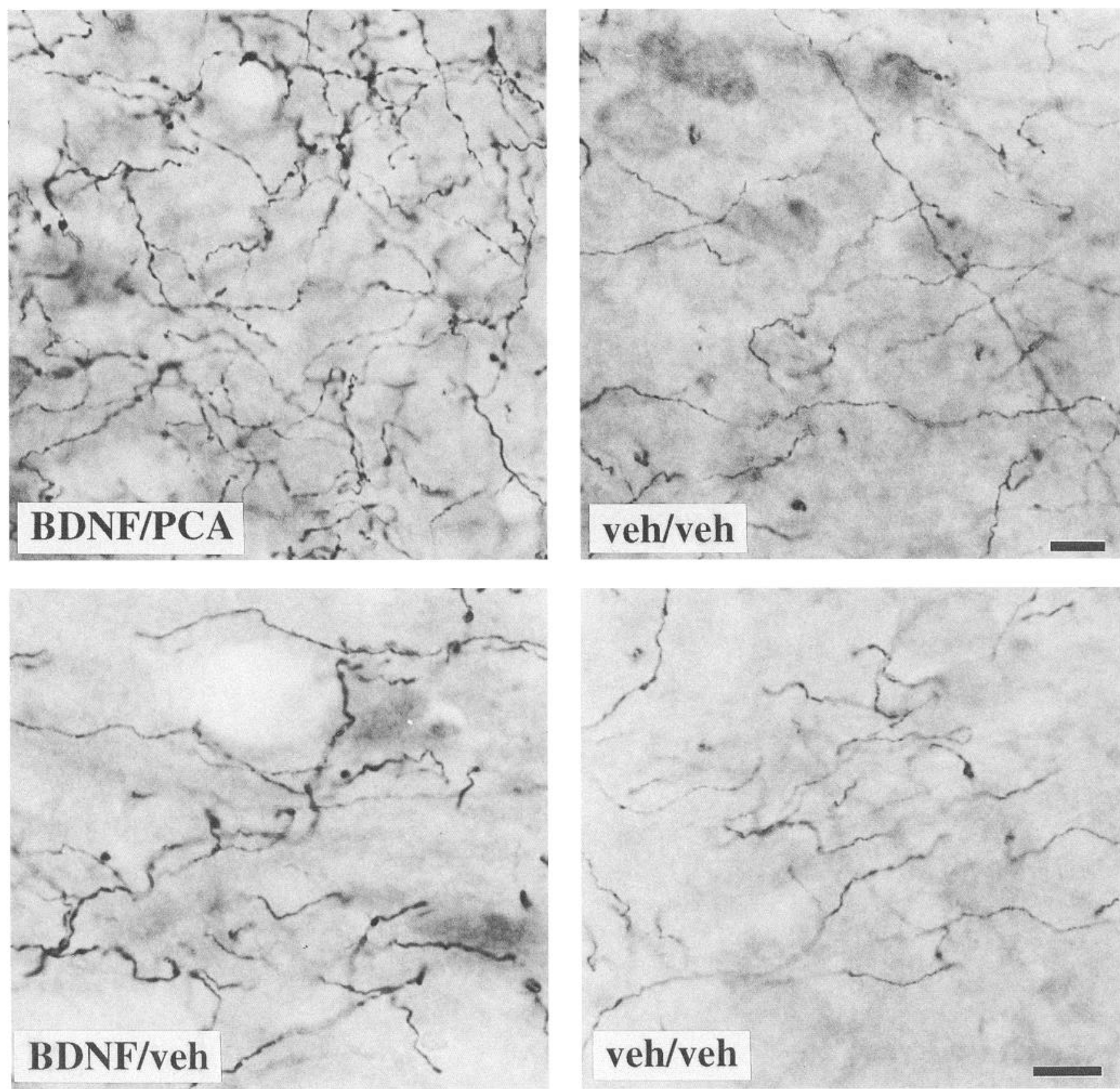

Figure 4. The morphology of serotonergic axons exposed to BDNF. In addition to the higher fiber density, the BDNF-exposed 5-HT axons in both PCA-lesioned (BDNF/PCA) and intact $(B D N F / v e h)$ rats appear to be slightly thicker, more intensely immunoreactive and more convoluted than those in the homologous cortex of control $(v e h / v e h)$ rats. Bright-field photomicrographs; note that the top two photographs are at a lower magnification than the bottom pair of photographs: scale bars for each pair, $10 \mu \mathrm{m}$.

cortical homogenates to determine whether BDNF was also acting through inhibition of the 5-HT uptake carrier. BDNF, in concentrations ranging from $20 \mathrm{pM}$ to $2 \mu \mathrm{M}$, did not inhibit the uptake of ${ }^{3} \mathrm{H}-5$-HT into cortical homogenates (Controls: $155 \pm$ $14 \mathrm{fmol} / \mathrm{mg}$ tissue vs $2 \mu \mathrm{M}$ BDNF: $151 \pm 13 \mathrm{fmol} / \mathrm{mg}$ tissue; $F_{6.23}=0.79$, NS). NT- 3 , in concentrations of 0.5 and $2 \mu \mathrm{M}$, also did not inhibit the uptake of ${ }^{3} \mathrm{H}-5-\mathrm{HT}$ into cortical homogenates (Controls: $122 \pm 13 \mathrm{fmol} / \mathrm{mg}$ tissue vs $2 \mu \mathrm{M}$ NT-3: $106 \pm 25$ $\mathrm{fmol} / \mathrm{mg}$ tissue; $F_{2,11}=0.38, \mathrm{NS}$ ).

\section{Discussion}

Serotonergic axons are normally found in high density throughout neocortex and other forebrain areas of the adult rat (Blue et al., 1988; Mamounas et al., 1991). Systemic administration of the amphetamine analog PCA causes a rapid degeneration of most 5-HT axons in forebrain, leading to a severe and longlasting denervation of cortex (Fuller and Snoddy, 1974; SandersBush et al., 1972; Mamounas et al., 1991, 1992). Using immunocytochemical and neurochemical methods, the present study has shown that continuous 3 week infusions of BDNF directly into the rat frontoparietal neocortex elicits a local sprouting response from uninjured serotonergic axons in the nonlesioned cortex and completely prevents the PCA-induced degenerative loss of 5-HT axons in the cortical area near the BDNF infusion cannula. This protective effect upon serotonergic axons is selec- 

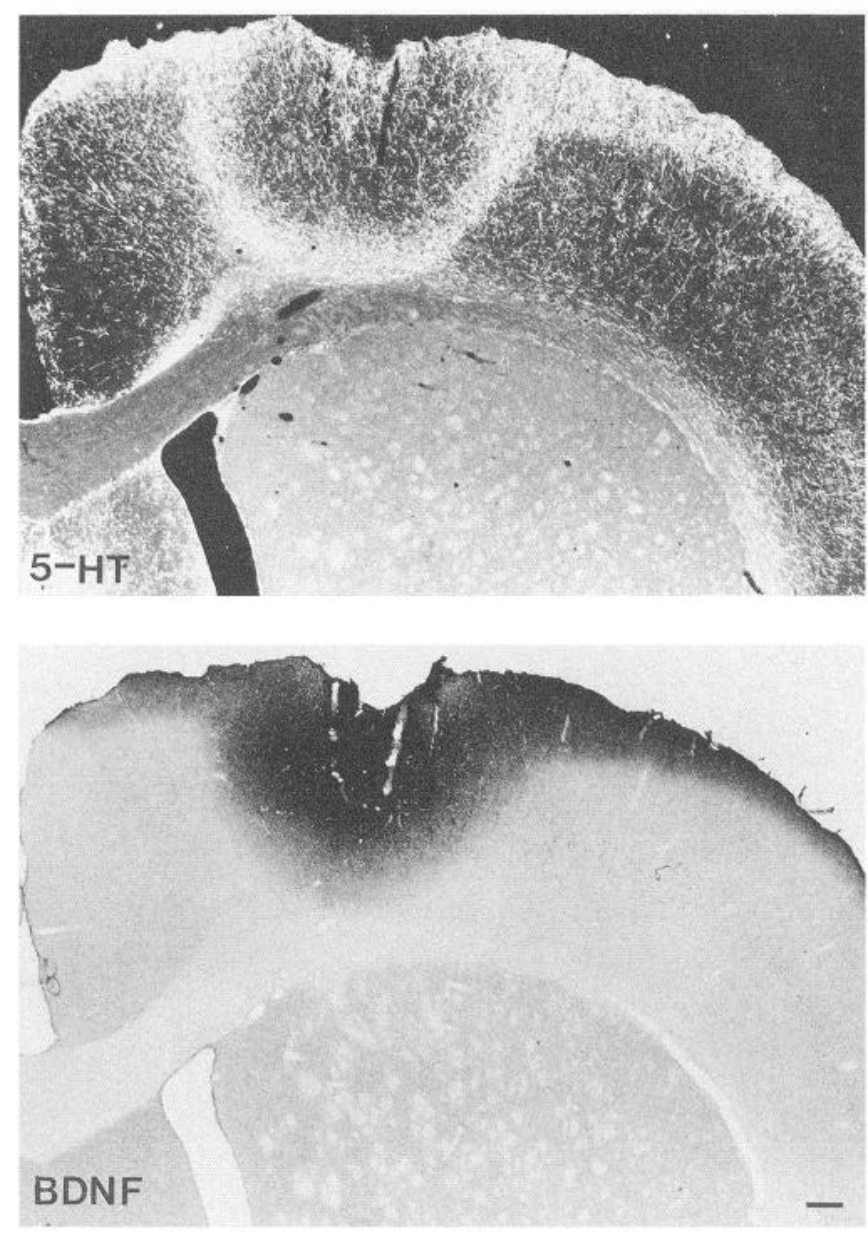

Figure 5. Correspondence between the distribution of spared 5-HT axons surrounding the BDNF infusion cannula in a $B D N F / P C A$ animal (top; dark-field photomicrograph) and the area of diffusion of exogenously delivered BDNF as determined by BDNF immunocytochemistry in an adjacent section (bottom; bright-field photomicrograph). The 5-HT axon density is highest along the perimeter of the area of BDNF diffusion. Note also the spread of the infused BDNF along the pial surface of cortex in this particular case, which is likewise associated with a high density of 5-HT axons at this location. Scale bar, $250 \mu \mathrm{m}$.

tive for BDNF since NT-3 caused only a partial sparing of the 5-HT innervation in PCA-treated rats, whereas infusions of vehicle, cytochrome $\mathrm{c}$, or NGF failed to prevent the PCA-induced loss of 5-HT axon density. Thus, BDNF is the first endogenous, neuronal-derived brain compound that has been shown to promote the survival or sprouting of serotonergic axons in the brain.

An important question that arises is whether BDNF prevents the PCA-induced loss of 5-HT axon density by rescuing serotonergic axons from degeneration, or by restoring the content of 5-HT back to detectable levels within otherwise structurally intact axons. One way of answering this question is by understanding the neurotoxic actions of PCA, itself. The ring-substituted amphetamines, including PCA, MDA, MDMA, and fenfluramine, belong to a class of compounds that cause, within hours, the release of 5-HT from nerve terminals followed by a prolonged depletion of brain 5-HT content (reviewed by Fuller and Henderson, 1994). Considerable evidence indicates that this long-term depletion of 5-HT results from the structural deterioration of 5-HT axons, as opposed to a reduction of 5-HT content within intact axons (reviewed by Axt et al., 1994). Within 2-3 d after PCA administration, extremely enlarged, fragmented 5-HT- and tryptophan hydroxylase-immunoreactive axon terminals are found in cortex, indicative of axonal degeneration (Axt et al., 1992, 1994). Silver impregnation studies reveal degenerating, argyrophilic axon terminals in striatum 1-2 d after MDMA, MDA or PCA administration (Ricaurte et al., 1985; Commins et al., 1987). Further evidence that these drugs cause axon degeneration is the presence of activated microglia (Wilson and Molliver, 1994) and astrocytes (Axt et al., 1994) in cortex between 1-6 weeks after treatment with PCA. The acute cytopathic changes are accompanied by a marked and long-lasting loss of 5-HT and 5-HIAA levels, 5-HT-immunoreactive axon terminals, tryptophan hydroxylase activity, high-affinity 5-HT uptake and binding sites for the 5-HT transporter in the forebrain (Sanders-Bush et al., 1972, 1975; Fuller and Snoddy, 1974; Ricaurte et al., 1985; Stone et al., 1987; Battaglia et al., 1988; Mamounas et al., 1991, 1992; Scanzello et al., 1993). These serotonergic deficits were shown to persist for at least 3-4 months and, in some studies, up to one year after drug treatment, thus strongly indicating 5-HT axon degeneration. In addition to the above parameters, retrograde and anterograde transport between terminal rich areas in cortex and 5-HT cell bodies in the raphe nuclei is nearly abolished at $3 \mathrm{~d}$ and for at least 6 weeks after PCA administration (Mamounas and Molliver, 1988; Haring et al., 1992; Axt et al., 1994). Despite the persistent loss of 5-HT in forebrain terminal fields after treatment with PCA, MDA, or MDMA, the serotonergic cell bodies in the raphe nuclei and the proximal portions of 5-HT axons in the major fiber pathways do not degenerate and remain intensely 5-HT-immunoreactive (Mamounas and Molliver, 1988; O'Hearn et al. 1988; Axt et al., 1994), arguing against a loss of serotonergic phenotype expression in these neurons. Thus, an extensive literature on PCA neurotoxicity indicates that the ability of BDNF to prevent the PCA-induced loss of 5-HT-immunoreactive axons most likely results from its ability to rescue serotonergic axons from degeneration or enhance their sprouting after damage, as opposed to restoring 5-HT transmitter expression within structurally intact axons. In the present study, the altered morphology and supranormal densities of BDNF-exposed 5-HT axons, and the attenuation of the PCA-induced loss of high-affinity ${ }^{3} \mathrm{H}-5$ HT uptake further support the view that BDNF acts upon the structural characteristics of serotonergic axons rather than upregulating 5-HT content alone.

There are two possible explanations for how BDNF may prevent the loss of serotonergic axon density that is normally seen 2 weeks after PCA administration. First, BDNF may prevent the PCA-induced degeneration of 5-HT axons. A second intriguing possibility is that the 5-HT axon terminals degenerate in the $B D N F / P C A$ animals but then, in the presence of BDNF, undergo a rapid and dramatically enhanced sprouting response during the 2 weeks after PCA administration. After chemical axotomy by PCA, endogenous sprouting of the damaged 5-HT axons in frontoparietal cortex does not begin until about 1-2 months later and only partly restores the normal innervation density by 6 months (Mamounas et al., 1992; Axt et al., 1994). In contrast to PCA, lesioning serotonergic fibers with the chemical neurotoxin 5,6dihydroxytryptamine causes a rapid sprouting that begins within 1 week in some brain areas, and results in a terminal plexus of normal density by one month and a hyperinnervation at longer survival times (Wiklund and Björklund, 1980). Thus, under favorable conditions, serotonergic neurons can respond to injury by rapid and vigorous sprouting. The possibility that exogenous 
Table 1. Effects of chronic intracortical infusion of BDNF on levels of 5-HT and 5-HIAA and high affinity ${ }^{3} \mathrm{H}-5-\mathrm{HT}$ uptake

\begin{tabular}{|c|c|c|c|c|}
\hline Treatment & Side of cortex & $\begin{array}{l}5 \text {-HT } \\
\text { (ng/mg } \\
\text { protein) }\end{array}$ & $\begin{array}{l}\text { 5-HIAA } \\
\text { (ng/mg } \\
\text { protein) }\end{array}$ & $\begin{array}{l}{ }^{3} \mathrm{H}-5-\mathrm{HT} \text { uptake } \\
\text { (fmol }{ }^{3} \mathrm{H}-5-\mathrm{HT} / \\
\mu \mathrm{g} \text { prot./ } \\
5 \mathrm{~min} \text { ) }\end{array}$ \\
\hline \multirow[t]{2}{*}{ veh/veh } & Infused (right) & $6.7 \pm 0.7^{n s .}$ & $2.9 \pm 0.3^{\text {ns. }}$ & $3.1 \pm 0.4^{n . s .}$ \\
\hline & Contralateral (left) & $\begin{array}{l}7.9 \pm 0.7 \\
(n=7)\end{array}$ & $\begin{array}{l}3.3 \pm 0.1 \\
(n=7)\end{array}$ & $\begin{array}{l}2.8 \pm 0.3 \\
(n=7)\end{array}$ \\
\hline \multirow[t]{2}{*}{ BDNF/veh } & Infused & $7.4 \pm 0.6^{\text {n.s. }}$ & $4.0 \pm 0.6^{n . s .}$ & $2.7 \pm 0.2^{n . s .}$ \\
\hline & Contralateral & $\begin{array}{l}6.3 \pm 0.7 \\
(n=8)\end{array}$ & $\begin{array}{l}3.4 \pm 0.5 \\
(n=7)\end{array}$ & $\begin{array}{l}2.7 \pm 0.2 \\
(n=8)\end{array}$ \\
\hline \multirow[t]{2}{*}{$v e h / P C A$} & Infused & $2.3 \pm 0.4^{\text {n.s. . }}$ & $1.0 \pm 0.2^{n . s . s . c}$ & $1.2 \pm 0.2^{n . s . c}$ \\
\hline & Contralateral & $\begin{array}{l}1.5 \pm 0.2 \\
(n=8)\end{array}$ & $\begin{array}{l}0.8 \pm 0.2 \\
(n=10)\end{array}$ & $\begin{array}{l}1.0 \pm 0.1 \\
(n=11)\end{array}$ \\
\hline \multirow[t]{2}{*}{$B D N F / P C A$} & Infused & $4.2 \pm 0.6^{a, b_{1} c}$ & $1.8 \pm 0.3^{a, b, c}$ & $1.4 \pm 0.1^{a, c}$ \\
\hline & Contralateral & $\begin{array}{l}0.8 \pm 0.2 \\
(n=9)\end{array}$ & $\begin{array}{l}0.6 \pm 0.1 \\
(n=12)\end{array}$ & $\begin{array}{l}0.7 \pm 0.1 \\
(n=10)\end{array}$ \\
\hline
\end{tabular}

BDNF $(12 \mu \mathrm{g} / \mathrm{d} ; B D N F /)$ or vehicle (veh/) were continuously infused for 3 weeks into right frontoparietal cortex. One week after the start of the infusion, rats were injected once subcutaneously with either PCA $(10 \mathrm{mg} / \mathrm{kg} ; / P C A)$ or vehicle (/veh). Two weeks after PCA, levels of 5-HT and 5-HLA.A and high affinity ${ }^{3}$ H-5-HT uptake were measured within a $3.0 \mathrm{~mm}$ diameter cylinder of cortical tissue centered over the infusion cannula (right side of cortex) and within a similar cylinder of cortical tissue from the contralateral, noninfused cortex. The data were analyzed using a $2 \times 2 \times 2$ (PCA treatment $\times$ BDNF infusion $\times$ side of cortex) analysis of variance with repeated measures on side of cortex, followed by the Newman-Keuls multiple range test. Data represent the mean \pm SEM.

13.s. Not statistically different from the corresponding, contralateral (noninfused) side of cortex $(p \geq 0.05)$.

"Different from the corresponding, contralateral side of cortex $(p<0.01)$.

D Different from veh/PCA, infused side of cortex $(p<0.05)$.

"Different from veh/veh, infused side of cortex $(p<0.005)$.

administration of BDNF facilitates the normally slow sprouting of PCA-damaged 5-HT axons is supported by several findings from this study. First, BDNF infusions can induce a robust sprouting of uninjured serotonergic axons, as evidenced by the substantially increased density and altered morphology of BDNF-exposed 5-HT axons in the nonlesioned cortex (BDNF/ $v e h)$. It is unlikely that this apparent hyperinnervation and altered morphology of 5-HT axons simply reflects a BDNF-induced upregulation of 5-HT content in existing axons, thereby revealing previously undetected serotonergic axons. In earlier studies (Blue et al., 1988; Mamounas and Molliver, 1988; Mamounas et al., 1991), monoamine oxidase (MAO) inhibitors were often used to enhance the intensity of 5-HT immunostaining by increasing the 5-HT content within axons; pretreatment with MAO inhibitors prior to fixation did not cause an apparent increase in the density or change in the morphology of serotonergic axons in intact or PCA-lesioned animals. Second, in the $B D N F / P C A$ animals, intracortical infusions of BDNF did not simply rescind the $\mathrm{PCA}$-induced loss of 5 -HT axons but, in many cases, markedly increased the serotonergic innervation density above the normal levels found in control (veh/veh) animals. Finally, the thicker and more convoluted morphology of the BDNF-exposed 5-HT axons in PCA-lesioned animals suggests that active sprouting mechanisms are invoked, as opposed to a sparing of existing axons. In current experiments, the temporal parameters of BDNF and PCA delivery are being manipulated to determine whether BDNF prevents the PCA-induced degeneration of serotonergic axons or dramatically facilitates and accelerates the sprouting of 5-HT axons after degeneration or both. We have preliminary evidence that 2 week infusions of BDNF started $4 \mathrm{~d}$ after PCA administration can markedly enhance the sprouting of prelesioned serotonergic axons (L. A.
Mamounas, M. E. Bluc, and C. A. Altar, unpublished observations). Based on the findings from other neurodegeneration models, a tropic role for the neurotrophins in promoting axonal growth after injury has been proposed, in addition to their role in supporting neuronal survival (reviewed by Gage et al., 1990). For example, after fimbria-fornix transection, exogenous administration of NGF causes sprouting of local cholinergic axons in the lateral septum (Williams et al., 1986) and promotes the regrowth of lesioned septal cholinergic fibers across a "grafting bridge" into the hippocampus (Hagg et al., 1990; Tuszynski et al., 1990). In addition to its effects upon axotomized neurons, NGF can elicit the sprouting of mature, uninjured sympathetic axons (Isaacson et al., 1992) and promote neurite growth from nonlesioned cholinergic neurons in the adult brain (Koliatsos et al., 1991; Tuszynski et al., 1991). Similarly, BDNF infusions in the present study elicited a robust sprouting of uninjured serotonergic axons in intact animals, thus supporting the proposal by Isaacson et al. (1992) that mature neuronal connections are continually being remodeled by tropic interactions. Interestingly, an endogenous hyperinnervation by serotonergic axons is observed in primary sensory cortex during neonatal development (D'Amato et al., 1987), similar to that seen in the BDNF-infused cortex of the adult. Further experiments are needed to determine whether this serotonergic hyperinnervation during development as well as the endogenous sprouting of 5-HT axons after PCA or 5,6-dihydroxytryptamine are associated with the increased expression of BDNF or its receptor in the brain.

The size of the cortical area protected from serotonergic denervation by the BDNF infusion (about $3 \mathrm{~mm}$ in diameter) is virtually identical to the area of diffusion of BDNF as determined by innunocylochemistry in an adjacent section (Fig. 5). Interestingly, in both the PCA-lesioned and intact rats, there was 

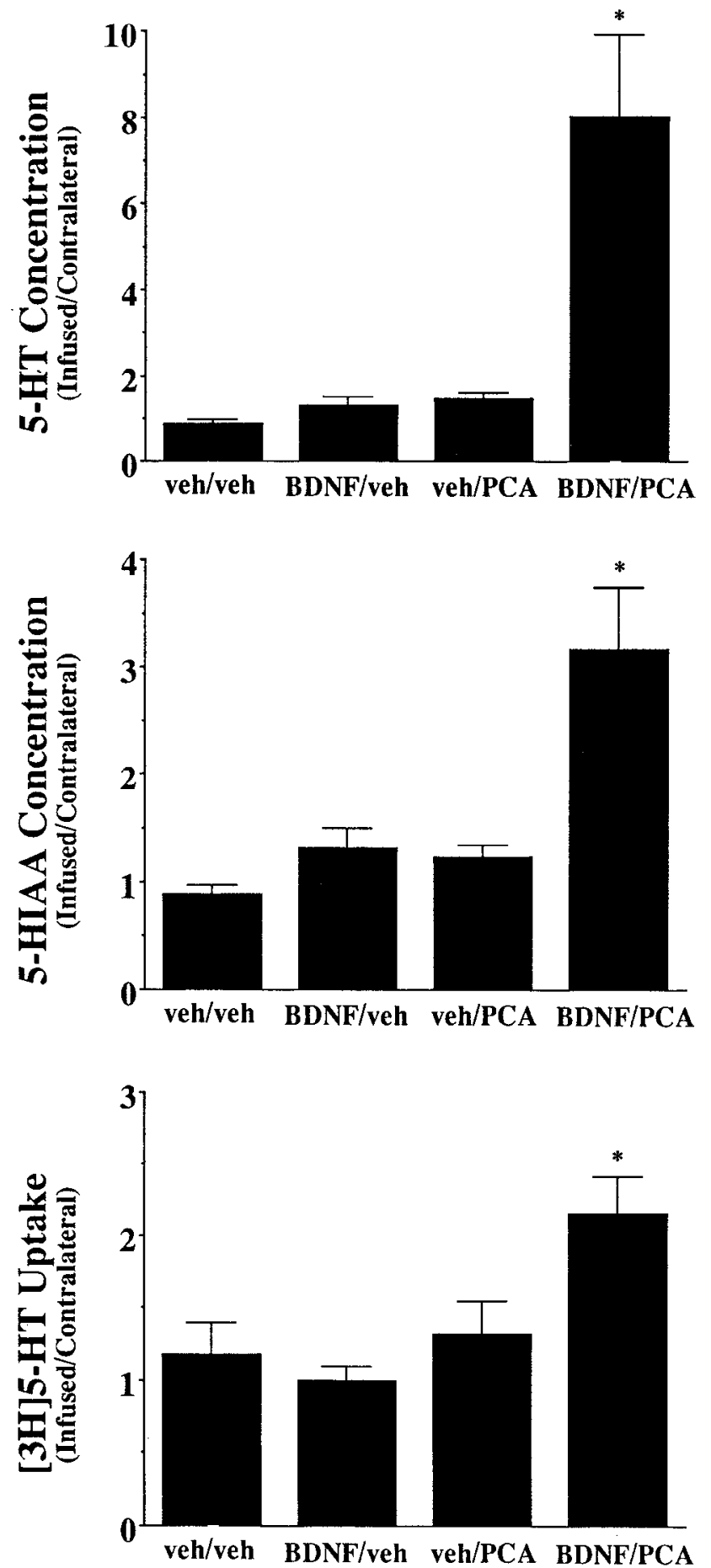

Figure 6. Levels of 5-HT (top histogram) and 5-HIAA (middle) and high affinity ${ }^{3} \mathrm{H}-5$-HT uptake (bottom), expressed as the ratio of the neurochemical value in the infused (right) cortex relative to the contralateral (noninfused) cortex for each animal (see Table 1 for absolute values). The data were analyzed with a $2 \times 2$ (PCA treatment $\times$ BDNF infusion) ANOVA, followed by the Newman-Keuls multiple range test. For each neurochemical evaluation, the $B D N F / P C A$ group differed significantly from the three other groups, while none of the other group differences reached statistical significance; ${ }^{*}, p<0.05$.

often a striking annulus of higher 5-HT axon density beginning about $0.5-1 \mathrm{~mm}$ from the BDNF infusion cannula (Fig. 2). This localized area of 5-HT hyperinnervation could represent an optimal concentration of BDNF for effects on 5-HT axons or could result from glial or other reactions closer to the cannula tip that are less favorable to 5-HT axon growth. The neurochemical evaluations in this study supported the immunocytochemical data, but were less sensitive in detecting the effects of BDNF on 5-HT axons. Using neurochemistry, the BDNF infusions in PCA-lesioned animals yielded only a partial recovery of 5-HT and 5-HIAA levels and high affinity ${ }^{3} \mathrm{H}-5-\mathrm{HT}$ uptake, and these measures were not significantly elevated in the BDNF infused cortex of intact animals (Table 1). Thus, the BDNF-induced 5-HT hyperinnervation ohserved with immunocytochemistry is not fully reflected in the neurochemical measures. This reduced apparent effect with the neurochemical procedures most likely results from the discrete localization of higher 5-HT axon density within a narrow annulus $(0.5-1 \mathrm{~mm}$ wide), thereby including lesser affected tissue within the $3 \mathrm{~mm}$ diameter punch surrounding the cannula site.

Among the neurotrophins examined in this study, the selectivity of BDNF in preventing the PCA-induced loss of 5-HT axons suggests that BDNF is acting via pharmacologically specific neurotrophin receptors in brain and supports the concept that the different neurotrophins activate distinct but overlapping neuronal populations. Consistent with our results that NGF was not neurotrophic for cortical 5-HT axons are the findings that NGF fails to clicit 5-HT neuritc outgrowth in embryonic raphe cultures (Azmitia et al., 1990), or cause serotonergic axon sprouting in the adult rat striatum (Kawaja and Gage, 1991), despite its ability to promote robust sprouting of cholinergic (Williams et al., 1986; Kawaja and Gage, 1991) and sympathetic (Isaacson et al., 1992) fibers. Moreover, NT-3, in this study, was considerably less potent than BDNF in promoting the survival of serotonergic axons after PCA, which remarkably parallels the relative potencies of these neurotrophins in augmenting 5-HT metabolism and analgesia (Siuciak et al., 1994). NGF and BDNF activate high affinity $\operatorname{TrkA}$ and TrkB receptors, respectively, while NT-3 preferentially activates TrkC and less potently stimulates the TrkB receptor (Kaplan et al., 1991; Lamballe et al., 1991; Squinto et al., 1991). Thus, our findings suggest that the TrkB receptor mediates the neurotrophic effects of BDNF on serotonergic neurons. The cellular mechanisms responsible for the survival promoting actions of BDNF on 5-HT axons are not known. It is well established that inhibitors of the 5-HT transporter can completely block the PCA-induced degeneration of 5-HT axons (Fuller and Henderson, 1994). However, our results suggest that BDNF is not mediating its protective effects on 5-HT axons by inhibiting the 5-HT uptake carrier, since BDNF failed to inhibit the in vitro uptake of ${ }^{3} \mathrm{H}-5-\mathrm{HT}$ into cortical homogenates. Since the neurotrophins have been shown to increase catalase and glutathione reductase activity (Jackson et al., 1990; Spina et al., 1992) and PC.A neurotoxicity may be mediated by oxidative mechanisms (Steranka and Rhind, 1987; Stone et al., 1989), one intriguing possibility is that BDNF may protect serotonergic axons from PCA-induced damage by augmenting oxidative stress protective mechanisms.

The protective effects of BDNF on neurotoxin damaged 5-HT axons suggests that BDNF may have a physiologic role in regulating the survival of serotonergic neurons in the adult brain and may prove useful as a therapeutic agent in ameliorating the serotonergic loss that occurs during aging or disease. Further evidence supporting a physiological role of BDNF for serotonergic neurons are the presence of BDNF displaceable binding sites (Altar et al., 1993) and trkB mRNA (Merlio et al., 1992) in the dorsal raphe nucleus, the retrograde transport of BDNF 
from 5-HT terminal fields in cortex to cell bodies in the raphe nuclei (Anderson et al., 1995) and the in vivo regulation of serotonergic metabolism and function by BDNF (Altar et al., 1994; Martin-Iverson et al., 1994; Siuciak et al., 1994). Thus, exogenous BDNF appears to be capable of augmenting functional as well as structural aspects of serotonergic neurons. The ability of BDNF to induce the sprouting of intact serotonergic fibers and prevent the PCA-induced loss of 5-HT axons is of particular interest, inasmuch as BDNF mRNA levels are particularly abundant in the neocortex (Ernfors et al., 1990). Thus, cortical BDNF levels or trkB receptor activation may regulate the individual susceptibility of serotonergic axons to 5-HT neurotoxins such as PCA, MDA, MDMA, and fenfluramine. Moreover, the marked serotonergic pathology observed during aging (van Luijtelaar et al., 1992) or in Alzheimer's disease (Cross, 1990) could be due to decrements in local BDNF availability (Phillips et al., 1991). Therapeutic interventions that augment BDNF levels or its signal transduction pathways may prove useful during aging or in neurodegenerative disease by promoting the survival of serotonergic neurons or by inducing the compensatory sprouting of residual 5-HT axon terminals.

\section{References}

Agid Y, Javoy-Agid F, Ruberg M (1992) Biochemistry of neurotransmitters in Parkinson's disease. In: Movement disorders 2 (Marsden CD, Fahn S, eds), pp 166-230. New York: Butterworths.

Alderson RF, Alterman AL, Barde Y-A, Lindsay, RM (1990) Brainderived neurotrophic factor increases survival and differentiated functions of rat septal cholinergic neurons in culture. Neuron 5:297-306.

Altar CA, Criden MR, Lindsay RM, DiStefano PS (1993) Characterization and topography of high-affinity ${ }^{125} \mathrm{~J}$-neurotrophin- 3 binding to mammalian brain. J Neurosci 13:733-743.

Altar CA, Boylan CB, Fritsche M, Jones BE, Jackson C, Wiegand SJ, Lindsay RM, Hyman C (1994) Efficacy of brain-derived neurotrophic factor and ncurotrophin- 3 on neurochemical and behavioral deficits associated with partial nigrostriatal dopamine lesions. J Neurochem 63:1021-1032.

Anderson KD, Alderson RF, Altar CA, DiStefano PS, Lindsay RM, Wiegand SJ (1995) Distribution of exogenous BDNF and NGF delivered into the brain. J Comp Neurol, in press.

Appel NM, Contrera JF, De Souza EB "(1989) Fenfluramine selectively and differentially decreases the density of serotonergic nerve terminals in rat brain: evidence from immunocytochemical studies. J Pharmacol Exp Ther 249:928-943.

Axt KJ, Mullen CA, Molliver ME (1992) Cytopathologic features indicative of 5-hydroxytryptamine axon degeneration are observed in rat brain after administration of $d$ - and $l$-methylenedioxyamphetamine. Ann NY Acad Sci 648:244-247.

Axt KJ, Mamounas LA, Molliver ME (1994) Structural features of amphetamine neurotoxicity in the brain. In: Amphetamine and its analogs: psychopharmacology, toxicology, and abuse (Cho AK, Segal DS, eds), pp 315-367. San Diego: Academic.

Azmitia EC, Dolan K, Whitaker-Azmitia PM (1990) S-100 ${ }_{B}$ but not NGF, EGF, insulin or calmodulin is a CNS serotonergic growth factor. Brain Res 516:354-356.

Battaglia G, Yeh SY, De Souza EB (1988) MDMA-induced neurotoxicity: parameters of degeneration and recovery of brain serotonin neurons. Pharmacol Biochem Behav 29:269-274.

Blue ME, Yagaloff KA, Mamounas LA, Hartig PR, Molliver ME (1988) Correspondence between 5- $\mathrm{HT}_{2}$ receptors and serotonergic axons in rat neocortex. Brain Res 453:315-328.

Commins DL, Axt KJ, Vosmer G, Seiden LS (1987) Endogenously produced 5,6-dihydroxytryptamine may mediate the neurotoxic effects of para-chloroamphetamine. Brain Res 419:253-261.

Cross AJ (1990) Serotonin in Alzheimer-type dementia and other dementing illnesses. Ann NY Acad Sci 600:405-417.

D'Amato RJ, Blue ME, Largent BL, Lynch DR, Ledbetter DJ, Molliver ME, Snyder SH (1987) Ontogeny of the serotonergic projection to rat neocortex: transient expression of a dense innervation to primary sensory areas. Proc Natl Acad Sci USA 84:4322-4326.
Ernfors P, Wetmore C, Olson L, Persson H (1990) Identification of cells in rat brain and peripheral tissues expressing mRNA for members of the nerve growth factor family. Neuron 5:511-526.

Fuller RW, Henderson MG (1994) Neurochemistry of halogenated amphetamines. In: Amphetamine and its analogs: psychopharmacology, toxicology, and abuse (Cho AK, Segal DS, eds), pp 209-242. San Diego: Academic.

Fuller RW, Snoddy HD (1974) Long-term effects of 4-chloroamphetamine on brain 5-hydroxyindole metabolism in rats. Neuropharmacology 13:85-90.

Gage FH, Buzsáki G, Armstrong DM (1990) NGF-dependent sprouting and regeneration in the hippocampus. Prog Brain Res 83:357-370.

Gamache P, Ryan E, Svendsen C, Murayama K, Acworth IN (1993) Simultaneous measurement of the monoamines, metabolites and amino acids in brain tissue and microdialysis perfusates. J Chromatogr 614:213-220.

Hagg T, Vahlsing HL, Manthorpe M, Varon S (1990) Nerve growth factor infusion into the denervated adult rat hippocampal formation promotes its cholinergic reinnervation. J Neurosci 10:3087-3092.

Haring JH, Meyerson L, Hoffman TL (1992) Effects of parachloroamphetamine upon the serotonergic innervation of the rat hippocampus. Brain Res 577:253-260.

Hefti F, Hartikka J, Knüsel B (1989) Function of neurotrophic factors in the adult and aging brain and their possible use in the treatment of neurodegenerative diseases. Neurobiol Aging 10:515-533.

Hohn A, Leibrock J, Bailey K, Barde Y-A (1990) Identification and characterization of a novel member of the nerve growth factor/brainderived neurotrophic factor family. Nature 344:339-341.

Hyman C, Juhas $z$ M, Jackson C, Wright P, Ip NY, Lindsay RM (1994) Overlapping and distinct actions of the neurotrophins BDNF, NT-3, and NT-4/5 on cultured dopaminergic and GABAergic neurons of the ventral mesencephalon. J Neurosci 14:335-347.

Isaacson LG, Saffran BN, Crutcher KA (1992) Nerve growth factorinduced sprouting of mature, uninjured sympathetic axons. J Comp Neurol 326:327-336.

Jackson GR, Apffel L, Werrbach-Perez K, Perez-Polo JR (1990) Role of nerve growth factor in oxidant-antioxidant balance and neuronal injury. I. Stimulation of hydrogen peroxide resistance. J Neurosci Res 25:360-368.

Kaplan DR, Henstead BL, Martin-Zanca D, Chao MV, Parada LF (1991) The trk proto-oncogene product: a signal transducing receptor for nerve growth factor. Science 252:554-558.

Kawaja MD, Gage FH (1991) Reactive astrocytes are substrates for the growth of adult CNS axons in the presence of elevated levels of nerve growth factor. Neuron 7:1019-1030.

Knüsel B, Winslow JW, Rosenthal A, Burton LE, Seid DP, Nikolics K, Hefti F (1991) Promotion of central cholinergic and dopaminergic neuron differentiation by brain-derived neurotrophic factor but not neurotrophin-3. Proc Natl Acad Sci USA 88:961-965.

Koliatsos VE, Clatterbuck RE, Nauta HJW, Knüsel B, Burton LE, Hefti FF, Mobley WC, Price DL (1991) Human nerve growth factor prevents degeneration of basal forebrain cholinergic neurons in primates. Ann Neurol 30:831-840.

Lamballe F, Klein R, Barbacid M (1991) trkC, an new member of the trk family of tyrosine protein kinases, is a receptor for neurotrophin3. Cell 66:967-979.

Levi-Montalcini R (1987) The nerve growth factor 35 years later. Science 237:1154-1162.

Lindsay RM, Wiegand SJ, Altar CA, DiStefano PS (1991) Neurotrophic factors: from molecule to man. Trends Neurosci 17:182-190.

Liu JP, Lauder JM (1992) S-100ß and insulin-like growth factor-II differentially regulate growth of developing serotonin and dopamine neurons in vitro. J Neurosci Res 33:248-256.

Maisonpierre PC, Belluscio L, Squinto S, Ip NY, Furth ME, Lindsay RM, Yancopoulos GD (1990) Neurotrophin-3: a neurotrophic factor related to NGF and BDNF. Science 247:1446-1451.

Mamounas LA, Molliver ME (1988) Evidence for dual serotonergic projections to neocortex: axons from the dorsal and median raphe nuclei are differentially vulnerable to the neurotoxin $p$-chloroamphetamine (PCA). Exp Ncurol 102:23-36.

Mamounas LA, Mullen CA, O'Hearn E, Molliver ME (1991) Dual serotoninergic projections to forebrain in the rat: morphologically distinct 5-HT axon terminals exhibit differential vulnerability to neurotoxic amphetamine derivatives. J Comp Neurol 314:558-586. 
Mamounas LA, Wilson MA, Axt KJ, Molliver ME (1992) Morphological aspects of serotonergic innervation. Adv Biosci 85:97-118.

Martin-Iverson MT, Todd KG, Altar CA (1994) Brain-derived neurotrophic factor and neurotrophin-3 activate striatal dopamine and serotonin metabolism and related behaviors: interactions with amphetamine. J Neurosci 14:1262-1270.

McCann UD, Ricaurte GA (1994) Use and abuse of ring-substituted amphetamines. In: Amphetamine and its analogs: psychopharmacology, toxicology, and abuse (Cho AK, Segal DS, eds), pp 371-385. San Dicgo: Academic.

McCann UD, Ridenour A, Shaham Y, Ricaurte GA (1994) Serotonin neurotoxicity after $( \pm) 3,4$-methylenedioxymethamphetamine (MDMA; "Ecstasy"): a controlled study in humans. Neuropsychopharmacology 10:129-138.

Merlio J-P, Ernfors P, Jaber M, Persson H (1992) Molecular cloning of rat $t r k \mathrm{C}$ and distribution of cells expressing messenger RNAs for members of the trk family in the rat central nervous system. Neuroscience 51:513-532.

Molliver ME (1987) Serotonergic neuronal systems: what their anatomic organization tells us about function. J Clin Psychopharmacol $7: 3 \mathrm{~S}-23 \mathrm{~S}$

Morse JK, Wiegand SJ, Anderson K, You Y, Cai N, Carnahan J, Miller J, DiStefano PS, Altar CA, Lindsay RM, Alderson RF (1993) Brainderived ueurolrophic factor (BDNF) prevents the degeneration of medial septal cholinergic neurons following fimbria transection. J Neurosci $13: 4146-4156$

O'Hearn E, Battaglia G, De Souza EB, Kuhar MJ, Molliver ME (1988) Methylenedioxyamphetamine (MDA) and methylenedioxymethamphetamine (MDMA) cause selective ablation of serotonergic axon terminals in forebrain: immunocytochemical evidence for neurotoxicity. J Neurosci 8:2788-2803.

Phillips HS, Hains JM, Armanini M, Laramee GR, Johnson SA, Winslow JW (1991) BDNF mRNA is decreased in the hippocampus of individuals with Alzheimer's disease. Neuron 7:695-702.

Ricaurte G, Bryan G, Strauss L, Seiden L, Schuster C (1985) Hallucinogenic amphetamine selectively destroys brain serotonin nerve terminals. Science 229:986-988.

Rosenthal A, Goeddel DV, Hguyen T, Lewis M, Shih A, Laramee GR, Nikolics K, Winslow JW (1990) Primary structure and biological activity of a novel human neurotrophic factor. Neuron 4:767-773.

Sanders-Bush E, Bushing JA, Sulser F (1972) Long-term effects of $p$-chloroamphetamine on tryptophan hydroxylase activity and on the levels of 5-hydroxytryptamine and 5-hydroxyindole acetic acid in brain. Eur J Pharmacol 20:385-388.

Sanders-Bush E, Bushing JA, Sulser F (1975) Long-term effects of $p$ chloroamphetamine and related drugs on central scrotoncrgic mechanisms. J Pharmacol Exp Ther 192:33-41.

Scanzello CR, Hatzidimitriou G, Martello AL, Katz JL, Ricaurte GA
(1993) Serotonergic recovery after $( \pm) 3$,4-(methylenedioxy)methamphetamine injury: observations in rats. J Pharmacol Exp Ther 264: 1484-1491.

Siuciak JA, Altar CA, Wiegand SJ, Lindsay RM (1994) Antinociceptive effect of brain-derived neurotrophic factor and neurotrophin-3. Brain Res 633:326-330.

Spina MB, Squinto SP, Miller J, Lindsay RM, Hyman C (1992) Brainderived neurotrophic factor protects dopamine neurons against 6-hydroxydopamine and $N$-methyl-4-phenylpyridinium ion toxicity: involvement of the glutathione system. J Neurochem 59:99-106.

Squinto SP, Stitt TN, Aldrich TH, Davis S, Bianco SM, Radziejewski C, Glass DJ, Masiakowski P, Furth ME, Valenzuela DM, DiStefano PS, Yancopoulos GD (1991) trkB encodes a functional receptor for brain-derived neurotrophic factor and neurotrophin-3 but not nerve growth factor. Cell 65:885-893.

Steranka LR, Rhind AW (1987) Effect of cysteine on the persistent depletion of brain monoamines by amphetamine, $p$-chloroamphetamine and MPTP. Eur J Pharmacol 133:191-197.

Stone DM, Merchant KM, Hanson GR, Gibb JW (1987) Immediate and long-term effects of 3,4-methylenedioxymethamphetamine on serotonin pathways in brain of rat. Neuropharmacology 26:1677-1683.

Stone DM, Hanson GR, Gibb JW (1989) In vitro reactivation of rat cortical tryptophan hydroxylase following in vivo inactivation by methylenedioxymethamphetamine. J Neurochem 53:572-581.

Tuszynski MH, Buzsáki G, Gage FH (1990) Nerve growth factor infusions combined with fetal hippocampal grafts enhance reconstruction of the lesioned septohippocampal projection. Ncuroscicnce 36: $33-44$.

Tuszynski MH, UHS, Yoshida K, Gage FH (1991) Recombinant human nerve growth factor infusions prevent cholinergic neuronal degeneration in the adult primate brain. Ann Neurol 30:625-636.

Van Luijtelaar MGPA, Tonnaer JADM, Steinbusch HWM (1992) Aging of the serotonergic system in the rat brain: an immunocytochemical and neurochemical study. Neurobiol Aging 13:201-215.

Whitaker-Azmitia PM, Peroutka SJ (1990) The neuropharmacology of serotonin. Ann NY Acad Sci 600.

Wiklund L, Björklund A (1980) Mechanisms of regrowth in the bulbospinal serotonin system following 5,6-dihydroxytryptamine induced axotomy. II. Fluorescence histochemical observations. Brain Res 191:129-160.

Williams LR, Varon S, Peterson GM, Wictorin K, Fischer W, Björklund A, Gage FH (1986) Continuous infusion of nerve growth factor prevents basal forebrain neuronal death after fimbria fornix transection. Proc Natl Acad Sci US $\Lambda$ 83:9231-9235.

Wilson MA, Molliver ME (1994) Microglial response to degeneration of serotonergic axon terminals. Glia 11:18-34.

Zhou FC, Azmitia EC (1990) Neurolrophic factor for serotonergic neurons prevents degeneration of grafted raphe neurons in the cerebellum. Brain Res 507:301-308. 